\title{
Numerical analysis of fluid mixing in T-Type micro mixer
}

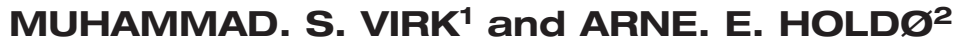 \\ Energy \& Environmental Technology Applied Research \\ Group Faculty of Engineering and Computing \\ Coventry University, Priory Street, Coventry CV1 5FB, UK, \\ E-mail: virkm@coventry.ac.uk¹, Arne.Holdo@coventry.ac.uk ${ }^{2}$
}

\begin{abstract}
Micro fluidic system holds promise for many novel applications within chemistry, biology and medicine. Mixing at micro scale with in a reasonable time period and length scale is important, but despite a large number of studied, no systematic study has been carried out so far to understand the effect of flow mechanism and geometry on micro fluidic mixing. Present study analyze the mixing of low Reynolds number $(<25)$ fluids in T-type passive micro mixer under various geometric and flow conditions to analyze their relative effects on mixing by diffusion and dispersion. CFD base steady state numerical simulations were carried out using finite element method. Results from this study shows that required mixing length increases with the increase of Reynolds number and mixing channel width, while there is a considerable decrease in mixing length with the increase of diffusion coefficient and mixing channel aspect ratio.
\end{abstract}

Keywords: Microfluidic Mixing; Reynolds Number; Peclet Number; Convection; Diffusion; Aspect ratio

\section{INTRODUCTION}

Micro fluidic devices have revolutionized the field of science especially biomedical and biochemical from last few years due to their wide applications in areas such as DNA assay, cell storing [1], high throughput screening, dynamic cell separators [2], surface patterning of cells, proteins and high throughput nucleic acid analysis [3] etc. Improvement, flexibility and performance of microfluidic systems incorporates a number of processes including fluid handling and fluid motion due to which mixing on micro scale has become a challenging problem [4] and have attracted the attentions of many new researchers. Mixing at micro level is not straight forward because of certain limitations such as low Reynolds number, low flow speed and small mixing length; moreover possibility to improve mixing by indulgence of turbulence is not practicable therefore mixing in such devices is totally diffusion dependant, which leads to complex design challenges.

Two different types of mixing generally occurs in micro fluidic devices, first is the heterogonous mixing created by convection and other is homogenous mixing caused by diffusion between adjacent domains [5]. Current development of micro mixers could be 
classified into two categories, active micro mixers where transverse flow is produced by oscillatory forcing with in the mixing channel and passive mixers where transverse flow is induced by the interaction of main stream with the specifically designed channel geometry [6]. In active mixers mixing efficiency can be adjusted by changing the input energy, while in passive micro mixers mixing is dependent upon mixer geometry or flow parameters [7]. Mixing methods suitable for macro scale mixing are some time not useable for micro scale mixing due to absence of turbulence, therefore different researchers have proposed different design topologies for improvement of mixing at micro level to induce fast mixing between fluid streams [8].

One such design approach is a $\mathrm{T}$ type rectangular channel micro mixer, where two fluid streams are able to diffuse across inlet of $\mathrm{T}$ junction before subsequent proceeding and uses the Interdiffusion of analyte and indicator to produce a signal change that can be correlated with the physical parameter such as analyte concentration [9]. In T channel large area to volume ratio gives prospect of better yield and selectivity than for conventional design, because diffusive fluxes of mass and heat transfer scales with area while source and sink are proportional to volume [10]. This configuration has been successfully applied for mixing of both gas and liquid fluids by different researchers [8, 11-13].

Present study mainly focuses upon improvement of mixing efficiency in T-type passive micro mixer having a rectangular channel, where two fluid streams of different concentrations are flowing parallel to each other. During this study attentions were focused to understand the variation effects of different flow parameters i.e. inlet flow velocity, diffusion coefficient and geometric parameters i.e. channel width, height and variation of mixing angle on mixing of fluids. Well defined flow conditions have special interest in context of micro devices, because of capability of low pressure drop, optimum residence and diffusion time. To obtain efficient mixing with in short residence times, contact area between regions of higher and low species concentrations needs to be highly increases, so that existing concentration gradients can be transferred to smaller scale for diffusively dominated dissipation [10]. Computational fluid dynamics (CFD) simulations are employed to determine the mixing of fluids for various deign and operating conditions during this study.

\section{MATHEMATICAL MODEL}

Figure-1 shows the geometric model and co-ordinates used for mixing characteristics analysis of fluid A and B in a T-type micro mixer. The origin of co-ordinates is located at the centre of mixing channel, where fluids stream start to meet. These analyses focused on the concentration distribution of fluids stream A \& B, having the same viscosity at different flow and geometric conditions. These fluids are mixing with the help of convective and diffusive transport. Equation-1 shows the species transport for incompressible fluid and is governed by $[6,14]$.

$$
\frac{\partial c}{\partial t}+u_{x} \frac{\partial c}{\partial x}+u_{y} \frac{\partial c}{\partial y}+u_{z} \frac{\partial c}{\partial z}=D\left[\frac{\partial^{2} c}{\partial x^{2}}+\frac{\partial^{2} c}{\partial y^{2}}+\frac{\partial^{2} c}{\partial z^{2}}\right]+R
$$

Where ' $c$ ' is the species concentration of fluid A, $u_{x}, u_{y}, u_{z}$ are the velocity components in $x, y$ and $z$ direction respectively, $D$ is the diffusion coefficient and $R$ is the rate of change of concentration of fluid A produced by chemical reaction. In the present study flow is assumed 


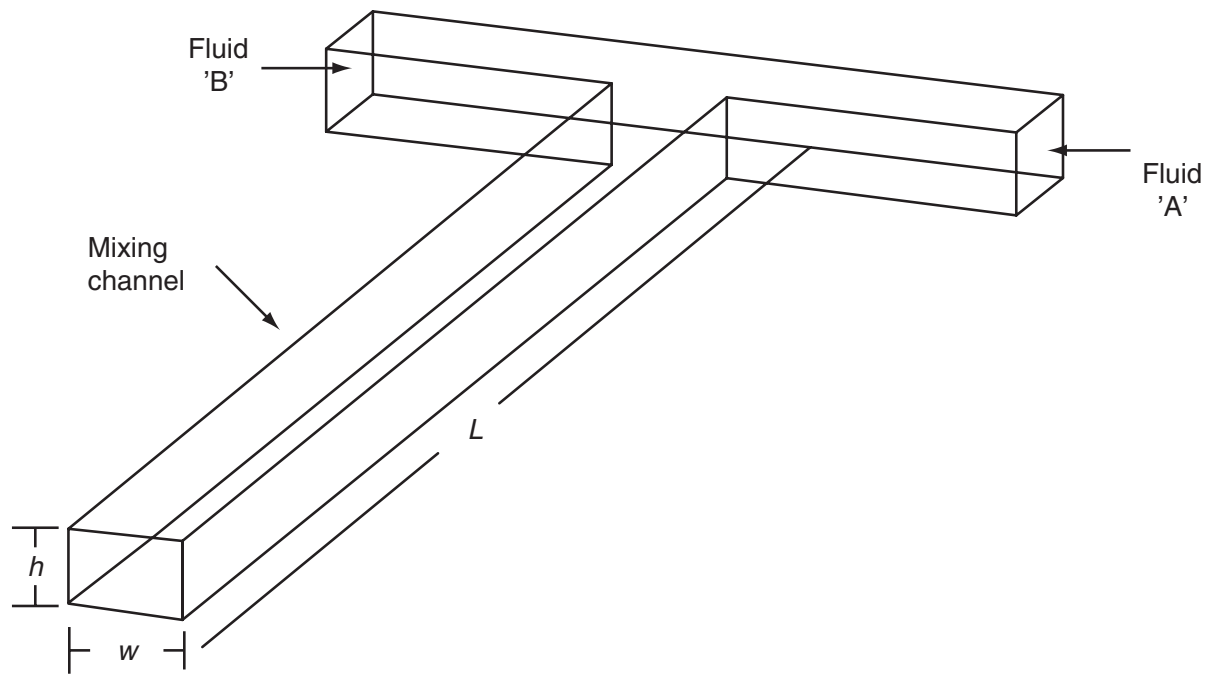

Figure 1 Schematic diagram of T-type micro mixer.

to be steady state, non reactive and fully developed, because of which Eq-01 could be reduced to

$$
u_{z} \frac{\partial c}{\partial z}=D\left[\frac{\partial^{2} c}{\partial x^{2}}+\frac{\partial^{2} c}{\partial y^{2}}\right]
$$

Due to low velocity and small channel size, Reynolds number is assumed to be very low $(<25)$, because of which viscosity plays a dominant role rather than inertia [15]. Purcell in his classic paper stated that [16] when $\operatorname{Re}>>1$, non linear term in Navier Stokes equation can be neglected and written as in form of Stokes equation.

$$
\rho \frac{\partial u}{\partial t}=-\nabla \mathrm{p}+\eta \nabla^{2} u+f
$$

In present study low speed laminar flow leads to low Reynolds number, due to which diffusion is dominant and mechanical agitation is ineffective, but in case of micro fluidic devices with micro channel of few hundreds micron length, diffusion is not efficient due to large diffusion path. A dimensionless number known as Peclet number expresses the relative importance of diffusion to convection. A simple estimate requires the particles to diffuse across the entire mixing channel, giving a diffusion time $\left(\mathrm{w}^{2} / \mathrm{D}\right)$, during which the fluid strip will move a distance ' $\mathrm{Z}$ ' $\left(\mathrm{U}_{\mathrm{o}} \mathrm{w}^{2} / \mathrm{D}\right)$ down to channel, so that channel width required for complete mixing would be of order

$$
Z / w \sim \frac{U_{o} w}{D} \equiv P e
$$

Convection and diffusion time in the mixing channel can be calculated using following relations [15], where $\mathrm{L}_{\mathrm{m}}$ is the mixing channel length and $\mathrm{w}$ is the channel width. 


$$
\begin{aligned}
& t_{c}=\frac{\mathrm{L}_{\mathrm{m}}}{\overline{\mathrm{u}}} \\
& t_{d}=\frac{\mathrm{w}^{2}}{4 \mathrm{D}}
\end{aligned}
$$

If $t_{c}>t_{d}$ then fluid can be diffused into each other completely by end of mixing channel, but in case of $t_{c}<t_{d}$, complete mixing is not possible with in available mixing length. Hence the least length for complete mixing can be stated as $L_{m}$,

$$
L_{m} \geq \frac{\mathrm{w}^{2}}{4 \mathrm{D}} \bar{u}
$$

\section{NUMERICAL SETUP}

For this study numerical simulations were carried out using finite element method, where unstructured triangular type mesh was used in coupled with a steady state non linear CFD solver. To make the CFD solution stable for low diffusion coefficients, concept of artificial diffusion was used because at very low diffusion coefficients convective term feed the numerical solution with energy, which does not only move the solution but also other small random fluctuations which are generally small, but when convective term feeds the solution with energy, they become large and destabilize the numerical solution. Dirichlet boundary conditions were used at flow inlet and outlet. Different geometric models were used at different flow conditions to analyze the effect of their variation on mixing of fluids. The study was done assuming channel width variation ranging from $150 \mu \mathrm{m}$ to $400 \mu \mathrm{m}$ and inlet flow velocity ranging from $0.05 \mathrm{~m} / \mathrm{s}$ to $0.3 \mathrm{~m} / \mathrm{s}$. Minimization of mixing length was selected as criteria of interest, under the influence of Peclet number, Reynolds number and convection / diffusion fluxes. Flow domain (mixing channel) was divided into different cross sections along horizontal and vertical directions to understand the mixing behaviour in detail.

\section{EFFECT OF PECLET NUMBER AND REYNOLDS NUMBER VARIATION}

Peclet number and Reynolds number are the function of diffusion coefficient and inlet flow velocity. This section presents a study about effect of Peclet number $\left(1\right.$ to $\left.10^{6}\right)$ and Reynolds number $(<25)$ variation on mixing of fluids. Here diffusion coefficient was varied ranging from order of $10^{-10}$ to $10^{-5} \mathrm{~m}^{2} / \mathrm{s}$. assuming equal inlet flow velocities on both inlets ranging from $0.01 \mathrm{~m} / \mathrm{s}$ to $0.3 \mathrm{~m} / \mathrm{s}$. Peclet number variation with respect to inlet velocity and diffusion coefficient was kept into consideration as a scale of measurement for mixing concentration because at small Peclet number diffusion dominates over convection and mixing occurs largely with in $\mathrm{T}$ junction while at high Peclet number a significant amount of mixing takes place in mixing channel at cost of large mixing length [8]. Mixing of fluid was analyzed with the help of CFD simulations; where for 3D analysis mixing channel was divided into 11 cross sections along channel width and 6 along channel length, average value of each parameter was taken across every cross section to understand this variation.

Figure-2( $\&$ \& $)$ show a parabolic profile of velocity variation across mixing channel, which means fluid velocity, is higher in centre of mixing channel; while near the wall it gets slow due to wall shear effects. High velocity causes high Reynolds number which leads to 
(a)

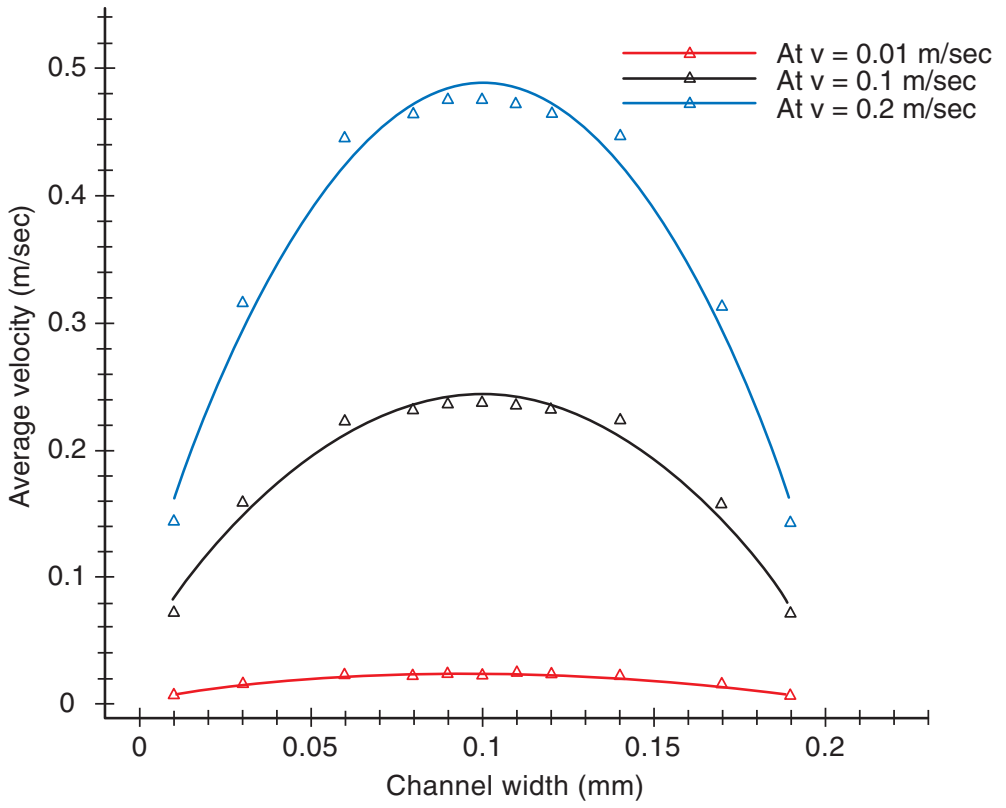

Figure 2(a) Velocity profile at different velocities.

(b)

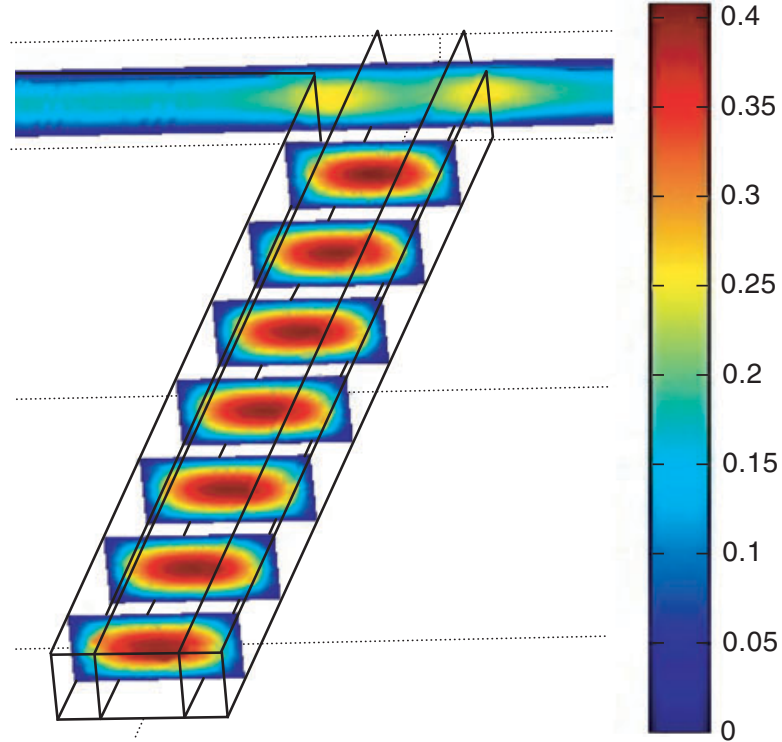

Figure 2(b) 3D Velocity profile at $v=0.1 \mathrm{~m} / \mathrm{sec}$

reduction in residence time that consequently effects the mixing of fluid; either the fluid is diffusion dominated or convection dominated. Such velocity profile also affects the interdiffusion zone between fluid streams flowing parallel to each other in mixing channel. Different researchers have studied this behaviour and proved that width of Interdiffusion 

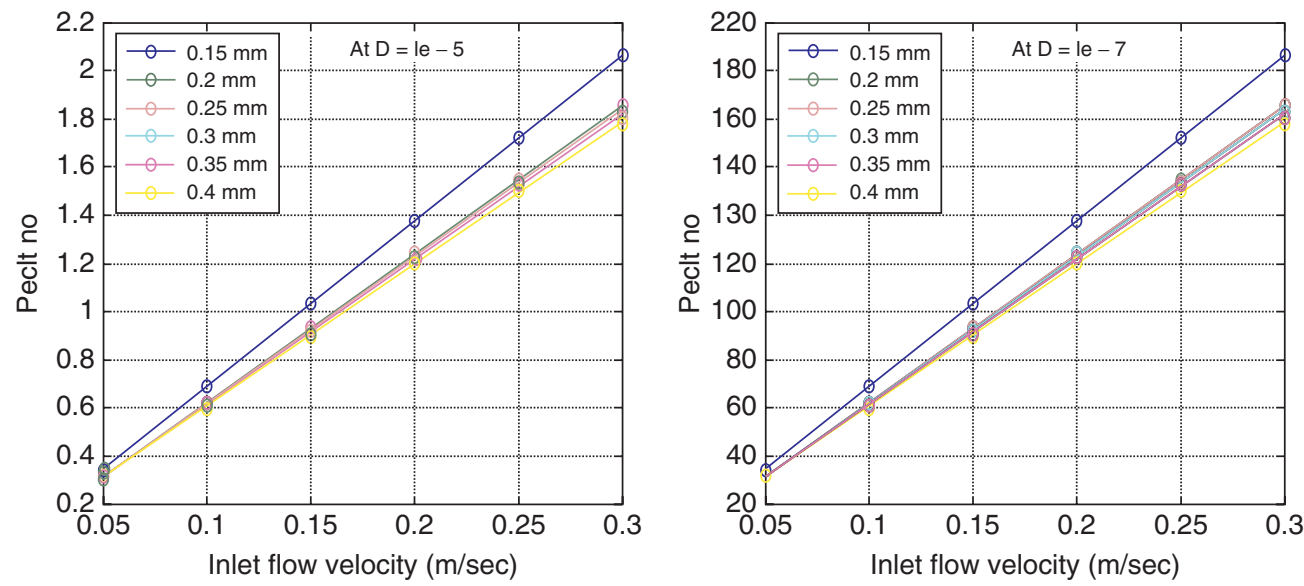

Figure 3 2D parametric study of Peclet number variation at different channel widths.

zone grow with $Z^{1 / 2}$ in centre of channel and near wall due to slow velocity it grows with $Z^{1 / 3}$ $[9,17]$. Near wall interfacial could be understood in more detail from classic problem of diffusion in shear flow studied by [18]. Parametric study shows that at high velocity wall shear affects the boundary layer considerably, which consequently affects the mixing parameters. Figure- 3 shows an increase of Peclet number with the increases of inlet velocity and decrease of diffusion coefficient.

To understand the variation of Peclet number in more detail a 3D study was carried out, which showed that at low velocities Peclet number is quite low in centre of mixing channel as compare to near walls, which shows the diffusion dominated mixing in centre of channel due to high diffusive flux. Figure-4(a \& b) provides a detailed overview of Peclet number variation at high and low diffusion coefficient considering different inlet velocities.

Results show that with the increase of diffusion coefficient from order of $10^{-10}$ to $10^{-6}$ $\mathrm{m}^{2} / \mathrm{s}$ effective values of Peclet number decreases considerably and mixing becomes diffusion dominated instead of convection. Such variation of Peclet number with diffusion coefficient attracted the attentions of researchers and made them to think about the scaling difference. Ismagilov stated in his paper [17] that such scaling difference is not due to actual change in nature of diffusion, but rather is skewed diffusive distribution that is the consequence of the 3D hydrodynamics of channel flow. Result shows a low Peclet number at centre of mixing channel for low velocity at all diffusion coefficients, which consequently gets increase with the increase of velocity, which means at low velocity convective flux is quite low in centre of channel and diffusive flux is quite high. A detailed parametric study is presented in figure$5(\mathrm{a} \& \mathrm{~b})$ to understand the variation of convective and diffusive flux with velocity and channel width.

Convective flux is the function of average concentration and velocity in the fluid domain. Parametric study in figure-5 (a \& b) shows that with the increase of Reynolds number convective flux increases to a considerable extant while variation of diffusive flux does not affect the convective flux. It means that with the increase of velocity at all diffusion coefficients mixing become convection dominated, which consequently leads to a high Peclet number. Similarly diffusive flux variation analysis in figure- 6 reveals that diffusive flux increases with the increase of diffusion coefficient, which leads to a diffusion dominated mixing. 
(a)

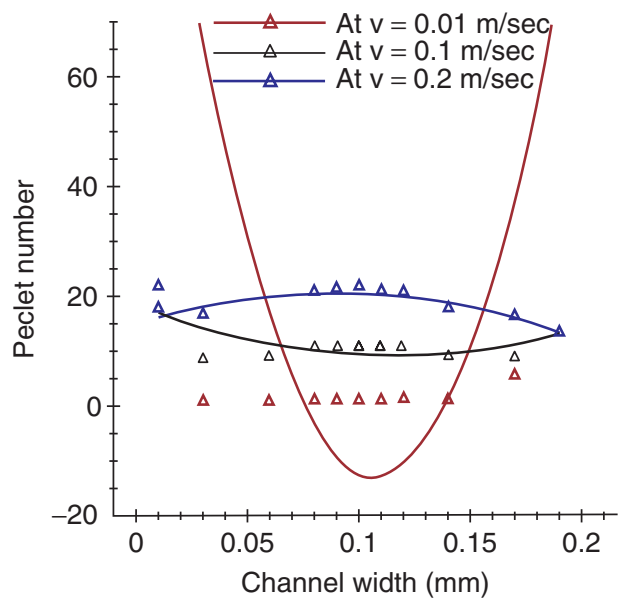

Figure 4a Peclet number variation at $D=10^{-6} \mathrm{~m}^{2} / \mathrm{s}$.

(b)

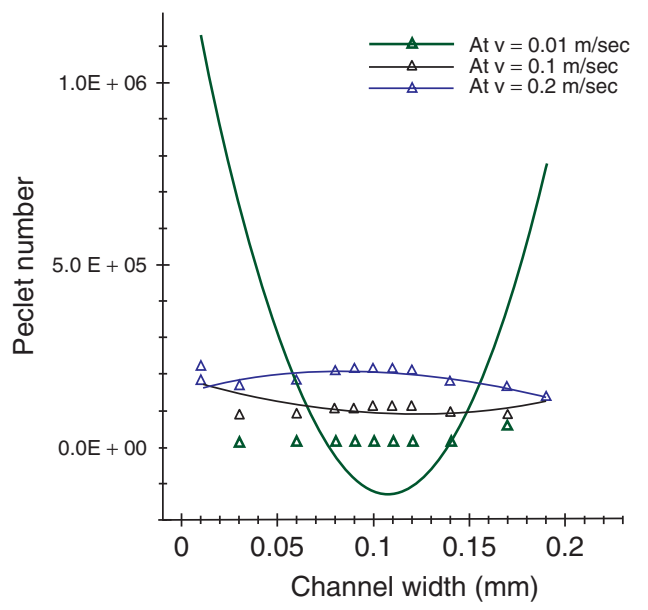

Figure 4b Peclet number variation at $D=10^{-10} \mathrm{~m}^{2} / \mathrm{s}$.

Diffusive flux is the function of diffusion coefficient and concentration gradient. Parametric analysis in figure-6 shows that at low Reynolds number diffusion coefficient have the maximum value and gradually with the increase of diffusion coefficient and inlet velocity diffusive flux decreases to a considerable extent, but on the other side at high diffusion coefficient i.e. $10^{-5} \mathrm{~m}^{2} / \mathrm{s}$, diffusive flux have high value at high velocity. This behaviour opened a new thought of research for better understanding of mixing. Such behaviour is due to increase in diffusion capability of mixing fluids. At high diffusion coefficient almost all the fluidic mixing is done with in the inlet channel therefore before reaching to mixing channel, almost both the fluids completely mixed up, but at low diffusion coefficient most of mixing is done in mixing channel, which is being effected by wall shear stresses. These wall shear stresses are affected by channel width and magnitude of inlet velocity. Therefore for low diffusion coefficients diffusive flux is high at small channel widths and velocities. Because at small channel widths concentration gradient along mixing channel is high due to 
(a)

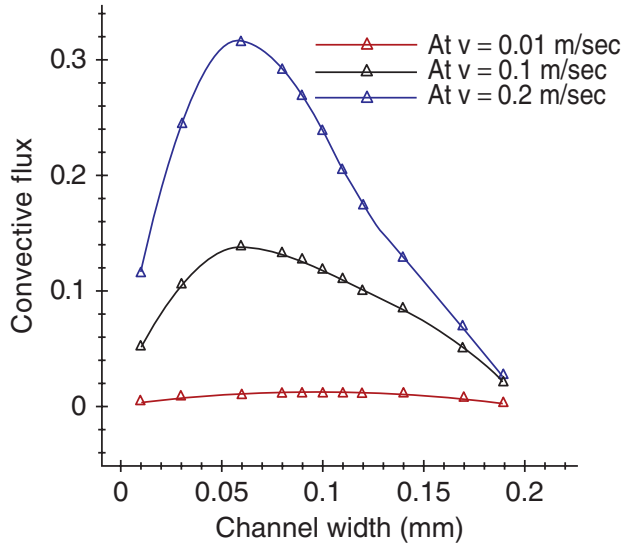

(b)

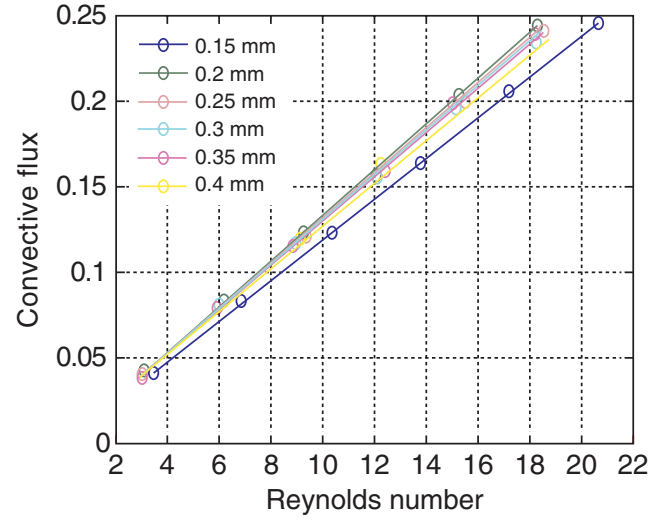

Figure 5 Parametric analysis of Convective flux variation at different Reynolds numbers.
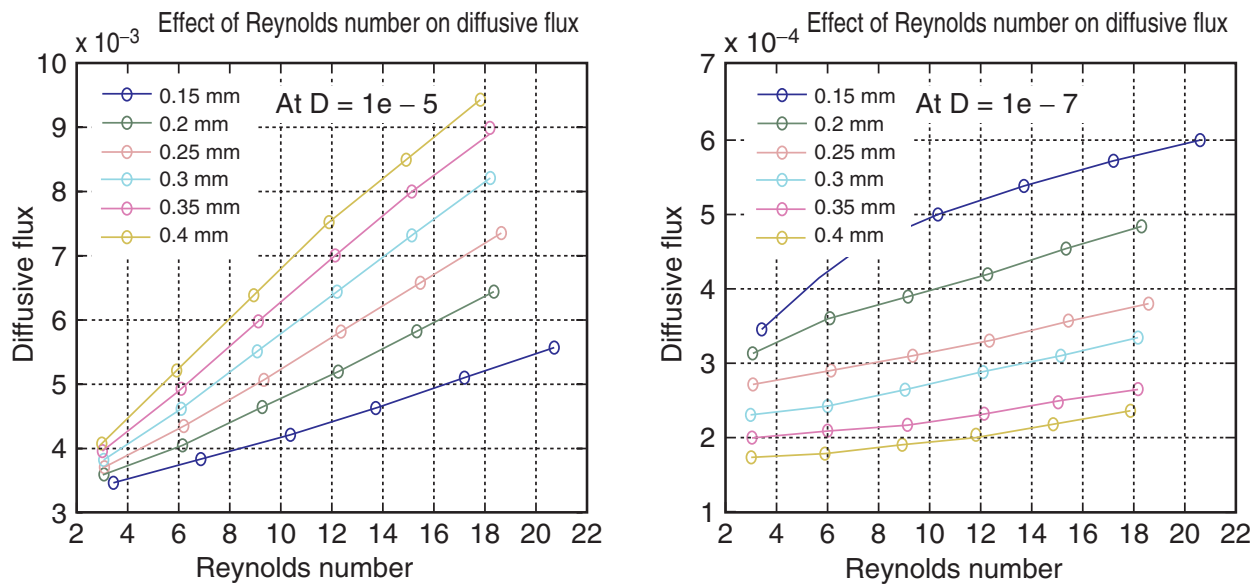

Figure 6 Parametric study of diffusive flux variation for different Reynolds numbers. 


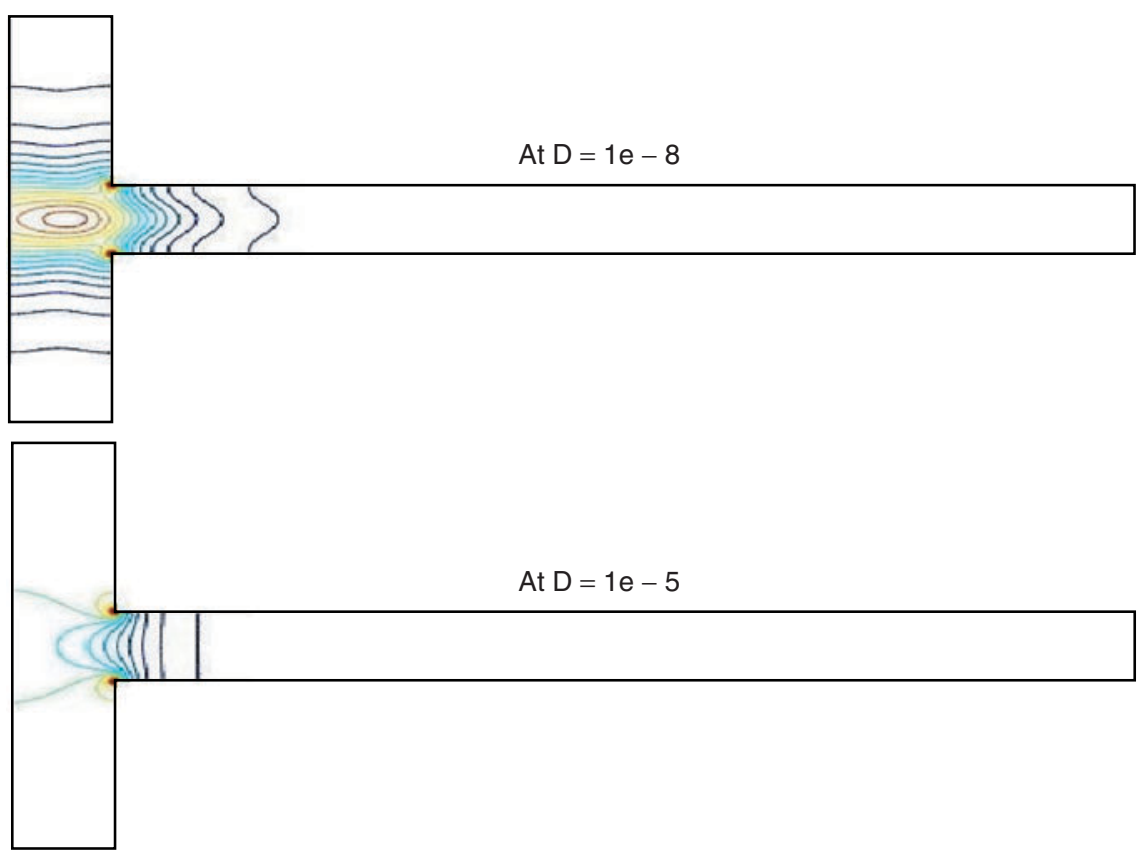

Figure 7 Mixing concentration gradient at different diffusion coefficient $\left(\mathrm{m}^{2} / \mathrm{s}\right)$.

high wall shear stresses, which leads to scaling difference of flow properties near wall. Figure-7 shows the concentration gradient variation at different diffusion coefficients and explains the above mentioned phenomena.

Variation of convective and diffusive flux consequently affects the mixing concentration and mixing length of fluids. Parametric analysis shows that with the increase of Reynolds number and Peclet number required mixing length increases to a considerable extent. Figure8 shows the parametric study about mixing length variation with Reynolds number at different diffusion coefficients.

Figure- 8 shows that with the increase of diffusion coefficient and decrease of Reynolds number mixing length decreases to a considerable extent in T-type micro mixer, which consequently improves the mixing concentration inside the mixing channel. Figure- 9 shows the variation of mixing concentration with the variation of inlet velocity. To understand the variation of concentration behaviour in more realistic way a detailed parametric study was done which explains the mixing in better way. Figure-9 shows the variation of mixing concentration with the variation of inlet velocity.

Analysis shows that with the increase of diffusion coefficient, mixing concentration increases and required mixing length for efficient mixing decreases to a considerable extent. Increase of inlet velocity leads to an increase in Reynolds number and figure- 9 shows that with the increase of inlet velocity mixing of fluid is being decreases, with in the available length and it requires more mixing length to complete the mixing. This is because of decrease in residence time of fluid, which consequently leads s to a high Peclet Number. But in case of high diffusion coefficient capability of molecular mixing of both the fluid streams is increased and even at high velocity there is a considerable increase in mixing with in available mixing length. 

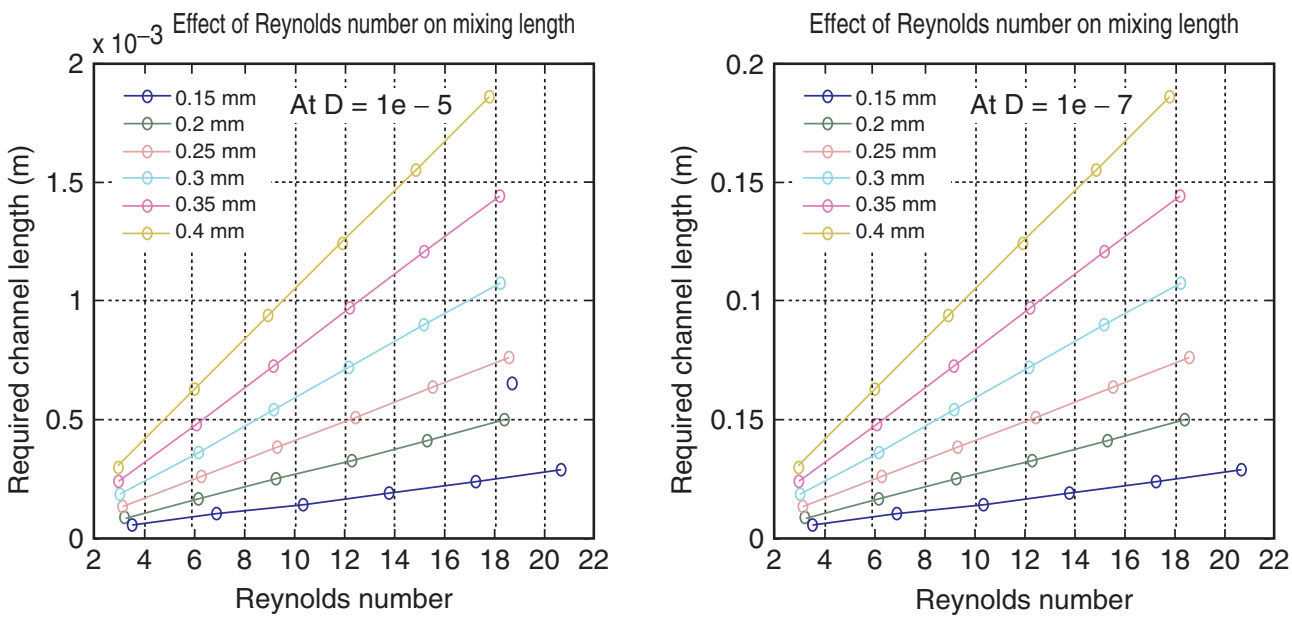

Figure 8 Mixing length variation with Reynolds number at different diffusion coefficient.
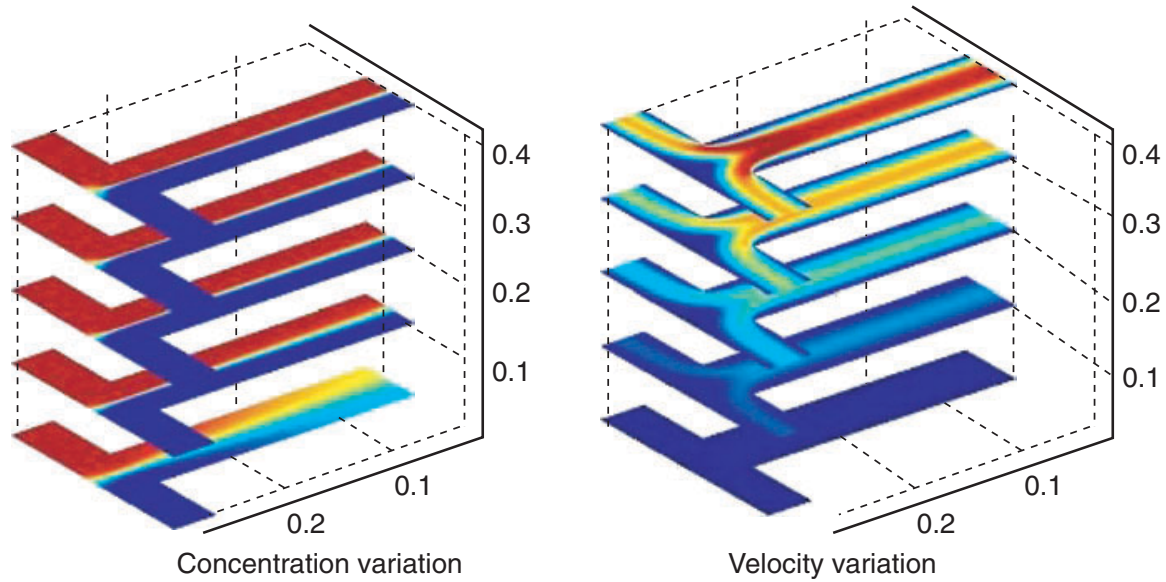

Figure 9 Variation of mixing concentration at diff $V=0.01,0.1,0.2,0.3 \& 0.4 \mathrm{~m} / \mathrm{s}$ respectively, At $D=10^{-8} \mathrm{~m}^{2} / \mathrm{s}$.

Figure-10(a \& b) shows the variation of mixing concentration at high and low diffusion coefficients at different inlet velocities and show good mixing concentration at available channel length in case of high diffusion coefficient. At low Reynolds number, due to concentration of analyte diffusing into the interior from very slow moving laminae near the walls the overall fluid concentration is high as compare to high Reynolds number. At low Reynolds number there is a sufficient time for interior portion of the channel to receive a significant amount of analyte from the wall region [9]. And when the fluid velocity reaches to zero this phenomenon become singularity because there is an infinite amount of time for such exchange. Base upon above mentioned analysis it can be concluded that diffusion coefficients and inlet fluid velocity variation leads to a considerable variation in Reynolds number and Peclet number which consequently affects 


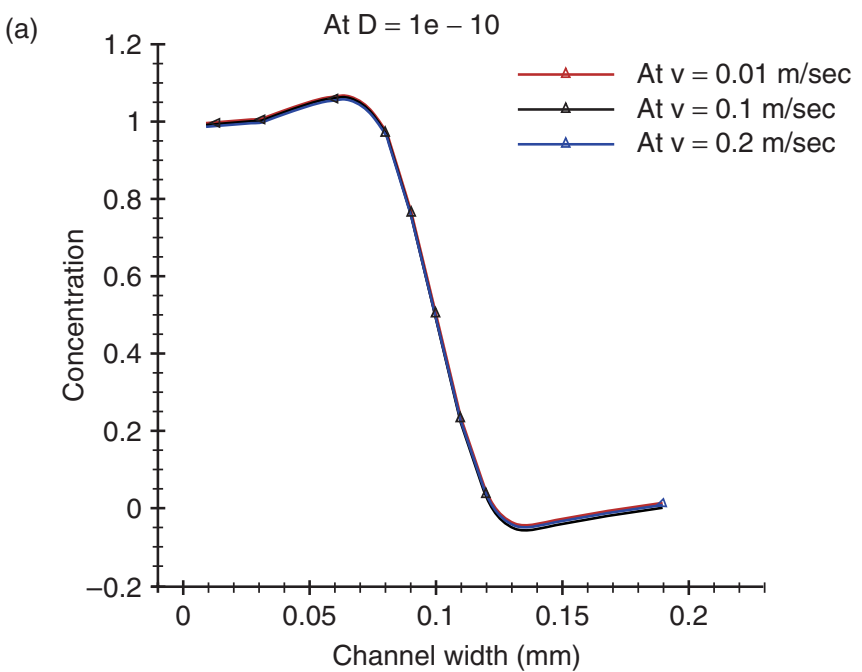

Figure 10a Variation of concentration at $D=10^{-10} \mathrm{~m}^{2} / \mathrm{s}$.

(b)

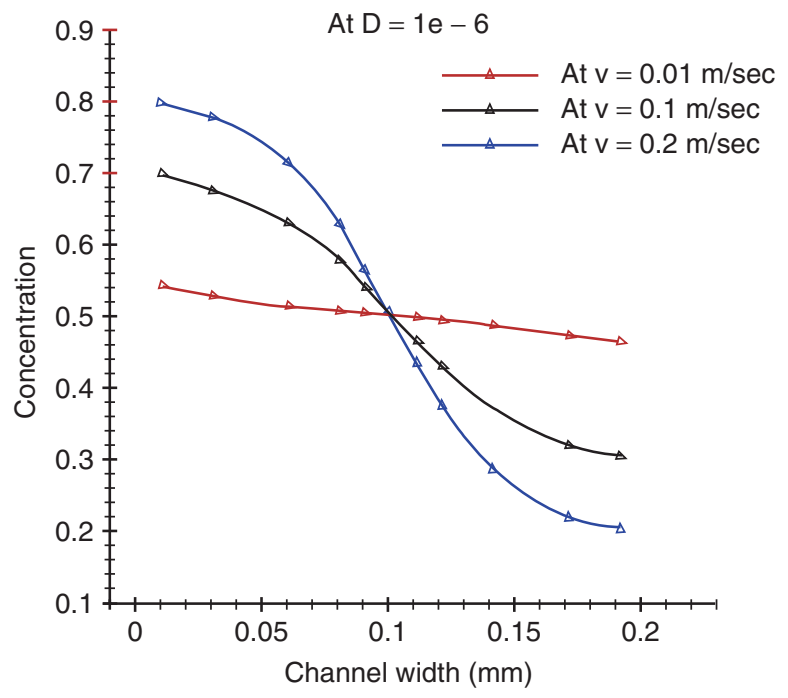

Figure 10b Variation of concentration at $D=10^{-6} \mathrm{~m}^{2} / \mathrm{s}$.

the mixing of fluids and improves the mixing in case of low Reynolds number and Peclet number.

\section{EFFECT OF ASPECT RATIO VARIATION}

Aspect ratio (height / width) ratio is one of the critical technical specifications for fabrication of micro channels. Mixing performance acts differently for different aspect ratios which consequently affects the required mixing length. Gobby, et al [19] investigated the effect of aspect ratio variation assuming a constant channel width, but current investigation is spread over variation of both mixing channel width and height considering following relation 


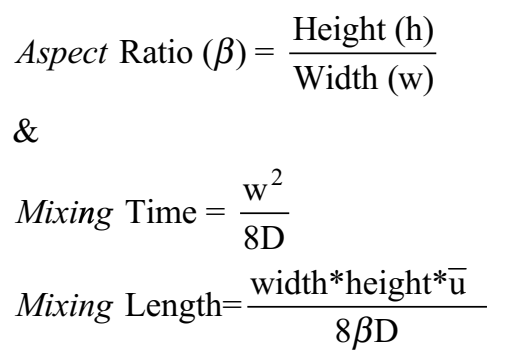

Different channel widths ranging from $100 \mu \mathrm{m}$ to $400 \mu \mathrm{m}$ and heights ranging from $75 \mu \mathrm{m}$ to $125 \mu \mathrm{m}$ were analyzed at different diffusion coefficients ranging from $10^{-10}$ to $10^{-5} \mathrm{~m}^{2} / \mathrm{s}$. Following sections presents a detailed study about affect of variation of mixing channel width and height individually on mixing of fluid at micro level.

\subsection{EFFECT OF CHANNEL WIDTH VARIATION}

This section presents study about effect of channel width variation on mixing in $T$ type passive micro mixer assuming equal inlet velocity at both inlets. Here channel width was varied from $100 \mu \mathrm{m}$ to $400 \mu \mathrm{m}$, assuming a constant channel height of $100 \mu \mathrm{m}$. Figure-11 $(a \& b)$ shows the variation of average velocity and corresponding Peclet number for three different channel widths where variation of velocity shows that with the increase of channel width average velocity across flow domain decreases while due to high side wall shear stress average velocity increases in case of low channels width, which consequently leads to a high Peclet number in centre of mixing channel.

Analysis shows that at low channel width Peclet number is high in centre of mixing channel, while at high channel widths Peclet number is low at centre of mixing channel and high near walls of mixing channel, but as over all Peclet number increases with the increase of channel width. Similarly parametric analysis show that with the increase of channel width Peclet number increases at all velocities and diffusion coefficients.

Figure-12 shows the variation of Peclet number with aspect ratio (height/width), and shows a decrease in Peclet number with the increase of aspect ratio, which means that with the increase of channel width Peclet number increases, which consequently reduces the mixing concentration. To understand this behaviour in more detail a comprehensive parametric study about variation of convective and diffusive flux with the variation of channel widths is done. Figure-13 show the variation of convective and diffusive flux at $\mathrm{D}=1 \mathrm{e}-7 \mathrm{~m}^{2} / \mathrm{s}$, at different inlet velocities.

Figure-13 shows that with the increase of channel width convective and diffusive flux increases at all velocities. But as over all diffusive flux gets increase with the increase of diffusion coefficient at all channel widths and velocities. Due to more surface contacts between mixing fluids and high wall shear effects, concentration gradient is high in case of small channel width, which leads to high diffusive flux. From variation of Peclet number along channel width it seems that mixing in case of small channel widths is convection dominated and will require more mixing length, but detailed analysis along channel width and channel length revealed that mixing in case of small channel widths is diffusion dominated. Figure-14 shows the variation of diffusive flux along mixing channel length.

High surface contacts between both fluid streams, width of Interdiffusion zone is high, which provide more chances to fluid molecules to diffuse across each other, which enhance 
(a)

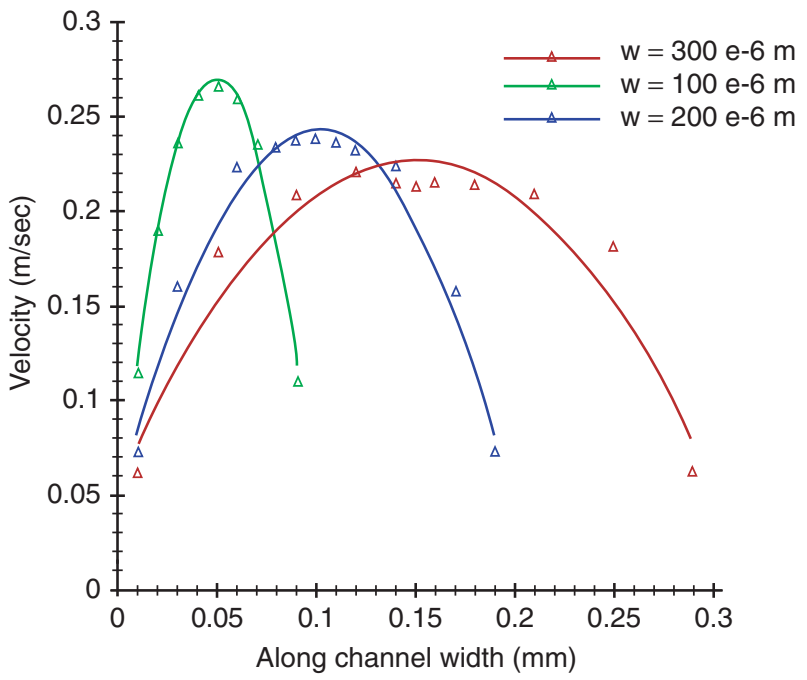

(b)

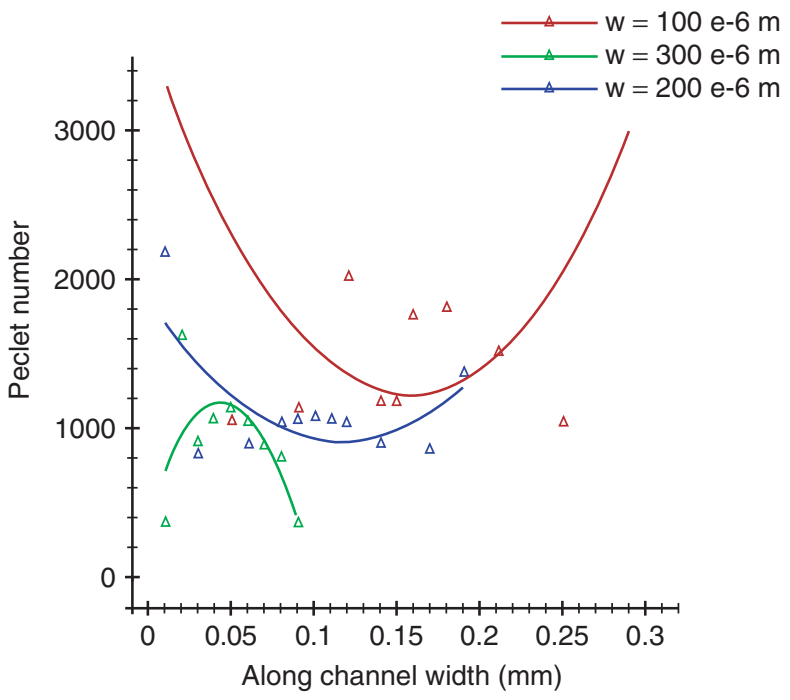

Figure 11 Variation of average velocity and Peclet number at different channel widths.

the mixing of fluids. Figure-15 (a\&b) shows the variation of convective and diffusive flux across mixing channel for different channel widths.

Analysis of figure $15(\mathrm{a} \& \mathrm{~b})$ show that with the increase of channel width diffusive flux reduces to a considerable extent, while there is no considerable change in the convective flux, although convective flux is high in case of low channel width due to high velocity. Variation of diffusive flux along channel width and length is high in case of small channel width, which causes high concentration gradients and improves mixing. Above discussion reveals that to improve the mixing efficiency in case of low diffusion coefficients and high fluid velocity, one way is to decrease the channel widths, because it will increase the mixing to some extent due to high interface of both fluid streams. Figure-16 shows the variation of 
(a)

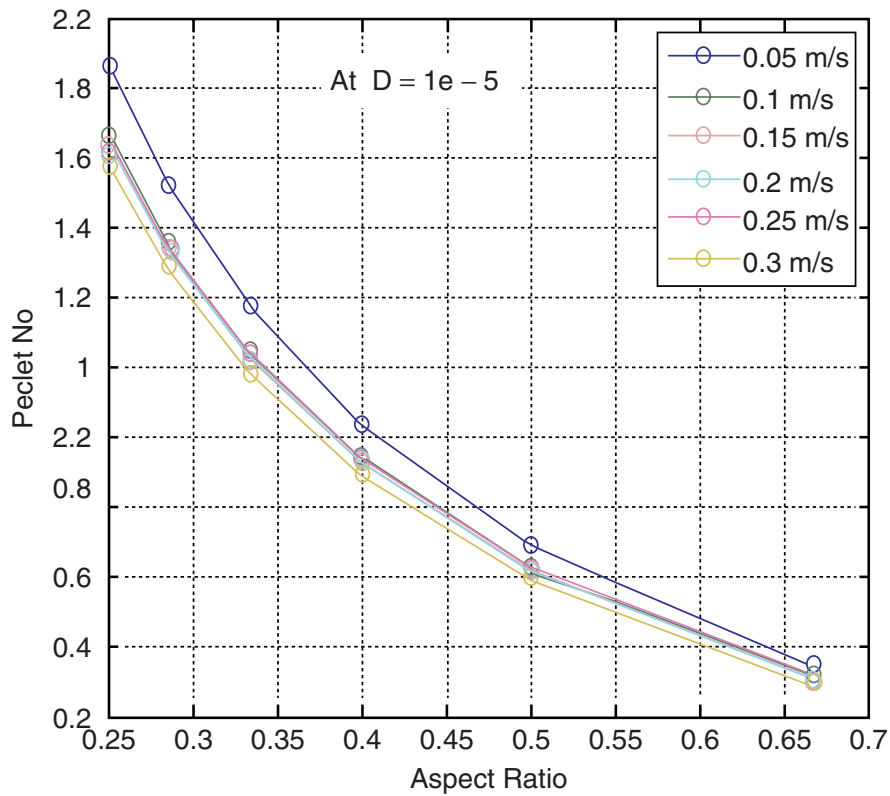

(b)

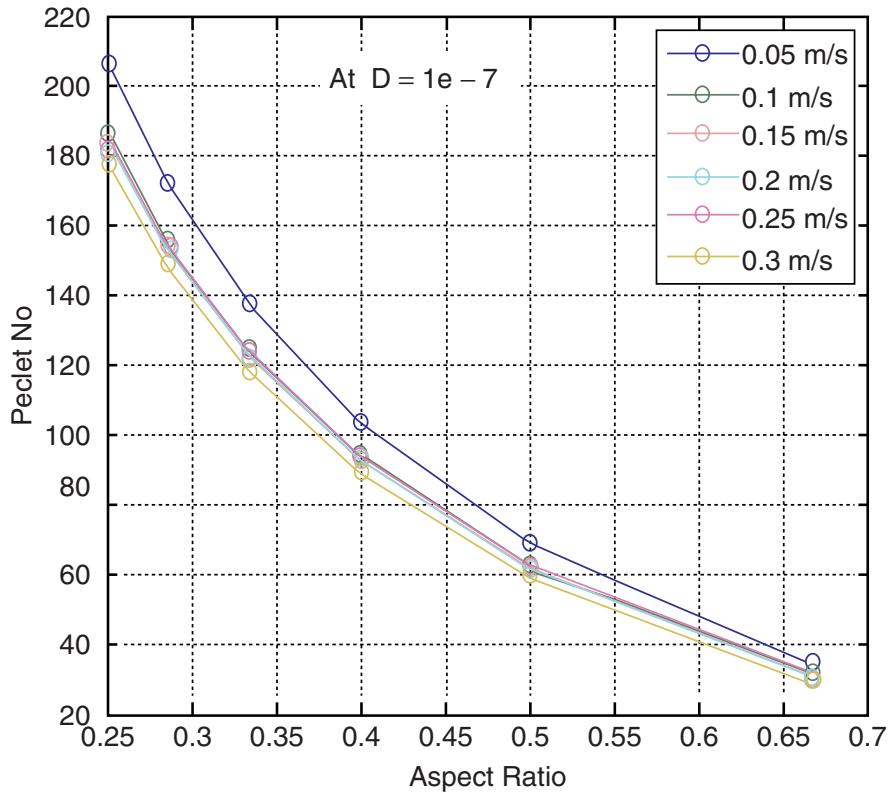

Figure 12 Variation of Peclet number with channel width at different diffusion coefficient $\left(\mathrm{m}^{2} / \mathrm{s}\right)$.

mixing concentration with the variation of channel widths at different velocities. It shows that as over all with the decrease of channel width mixing concentration improves to a considerable extant at all velocities, which means that required mixing length reduces to a considerable extent. 

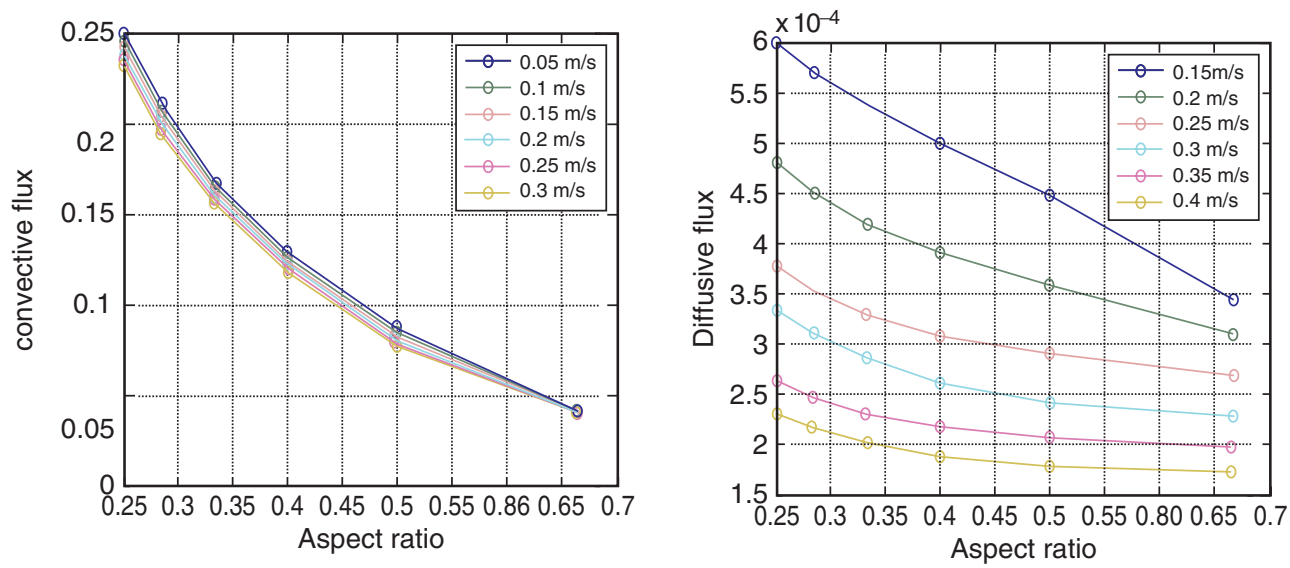

Figure 13 Variation of convective/diffusive fluxes with channel width at $D=1 e-7 \mathrm{~m} 2 / \mathrm{s}$.

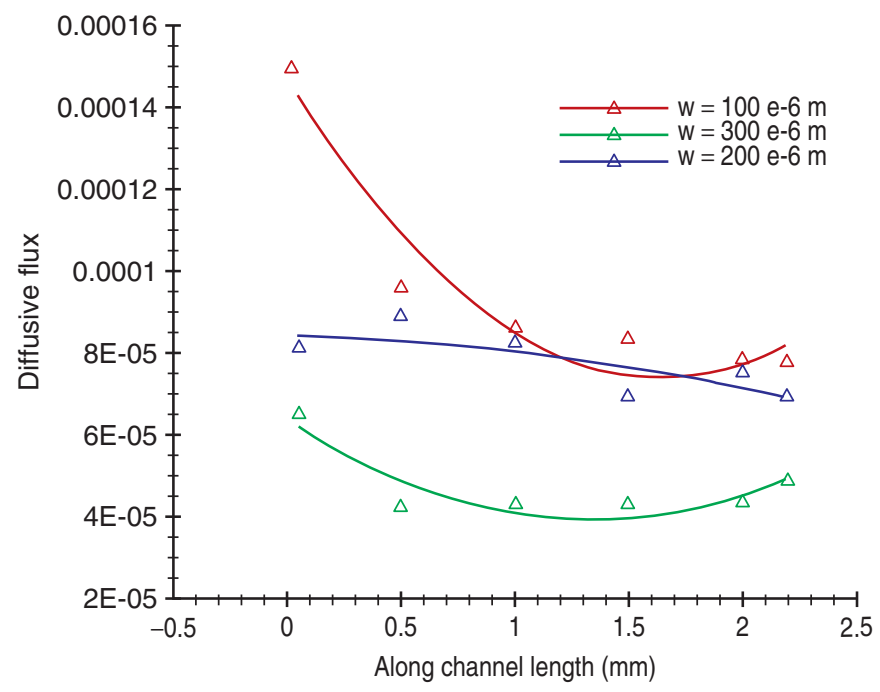

Figure 14 Variation of diffusive flux along channel length.

Figure-17 shows the variation of required mixing length with the variation of channel width at different velocities and diffusion coefficients.

\subsection{EFFECT OF CHANNEL HEIGHT VARIATION}

Three different channel heights ranging from $75 \mu \mathrm{m}$ to $125 \mu \mathrm{m}$ were analyzed at constant channel width of $200 \mu \mathrm{m}$ under steady state flow conditions to understand the effect of mixing channel height variation on mixing of fluid. All these analyses were done at constant diffusion coefficient of $1 \times 10^{-8}$ and fluid velocity of $0.1 \mathrm{~m} / \mathrm{s}$. Figure-18 (a\&b) shows the variation of average flow velocity and corresponding Peclet number with variation of mixing channel height. 
(a)

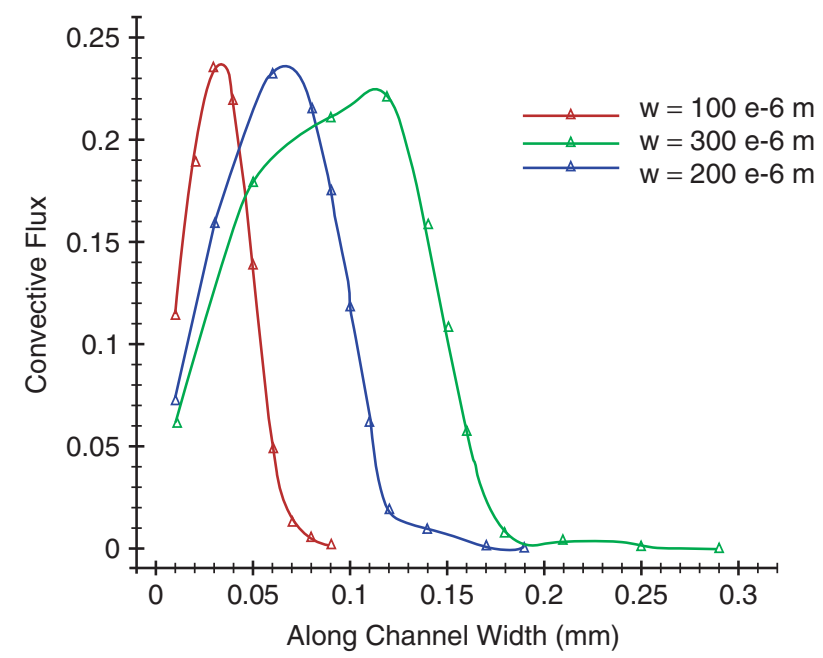

(b)

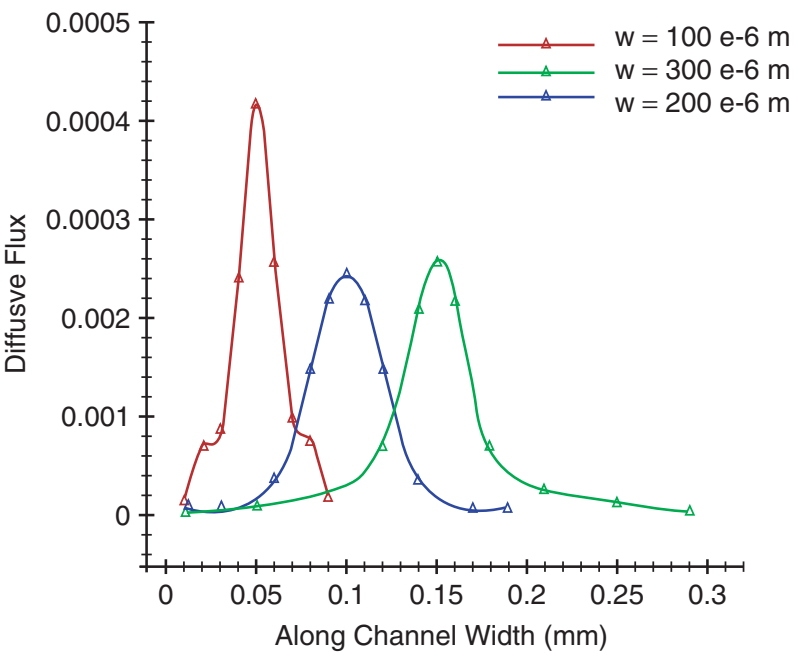

Figure 15 Variation of convective and diffusive flux across mixing channel along channel width.

Analysis show that with the increase of channel height average velocity increases, which consequently leads to an increase in Reynolds number and Peclet number. It means that with the increase of channel height aspect ratio gets increases, due to which wall shear stress due to upper and lower walls decreases [19], which consequently leads to an improvement in mixing of fluids. Variation of convective and diffusive flux shows that there is no considerable change in convective flux, but diffusive flux reduces considerably with the increase of channel height and as over all there is no considerable change in mixing concentration with the variation of channel height.

With the decrease of channel height, diffusive flux increases to a considerable extent, which means a high concentration gradient across channel width in mixing channel, but along channel length, when diffusive flux is analyzed, it shows a considerable decrease in diffusive flux with the reduction of channel height. Over all effect of variation of diffusive 


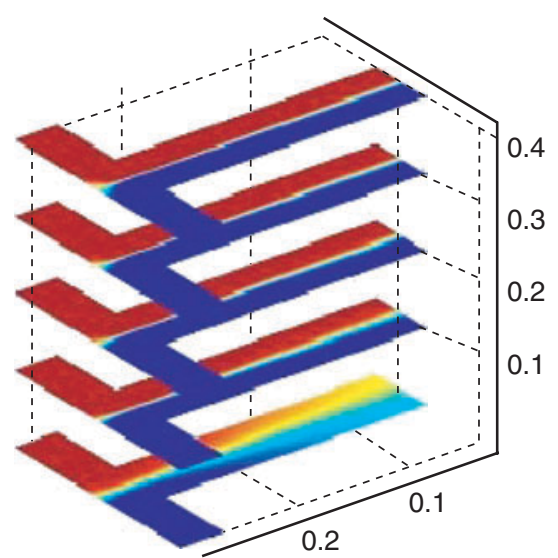

$A t=w 300 e-6 m$

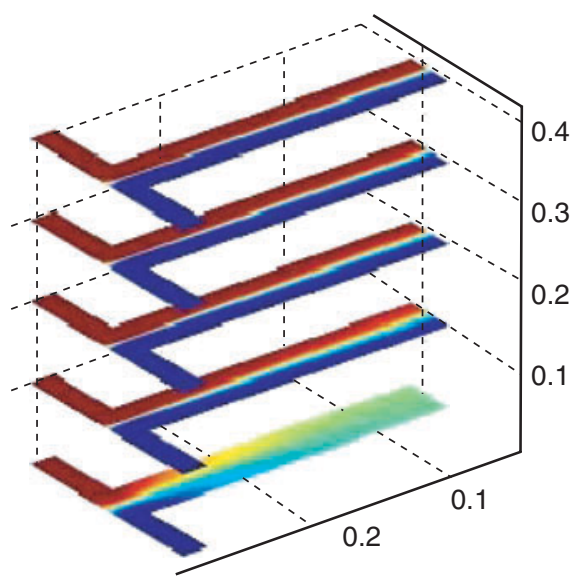

$A t=w 200 e-6 m$

Figure 16 Effect of variation of channel width on mixing concentration at $v=0.01$, $0.1,0.2,0.3 \& 0.4 \mathrm{~m} / \mathrm{s}$.
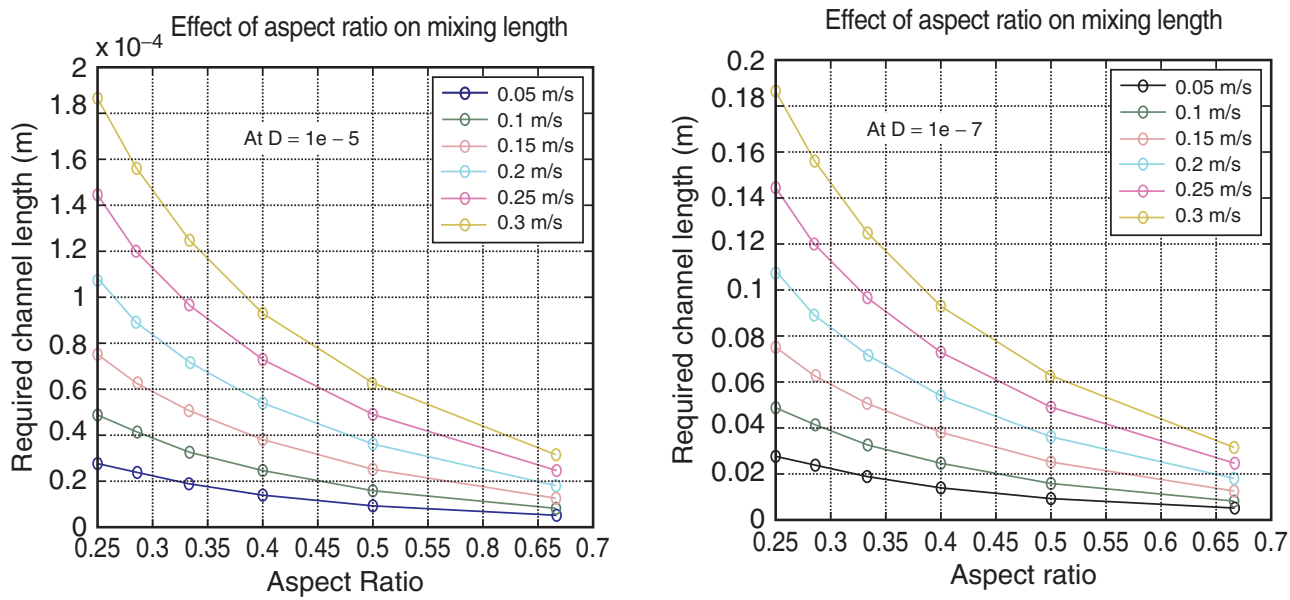

Figure 17 Effect of channel width variation on mixing length.

and convective flux with the variation of channel height shows that with the decrease of channel height mixing decreases to some extent. Although this variation is not significant, but it can be concluded that reduction in channel height leads to a reduction in mixing of fluid. Figure-19 shows the variation of mixing concentration with the variation of channel height at constant channel width $200 \mu \mathrm{m}$.

As over all study about the effect of variation of channel width and height reveals that with the increase of channel width aspect ratio decreases, which consequently leads to an increase in mixing length. Similarly on other side reduction in channel height, reduces the aspect ratio and increases the mixing length. Therefore as over all it can be concluded that with the decrease of aspect ration, mixing efficiency decreases and required mixing length and time increases to a considerable extent. 
(a)

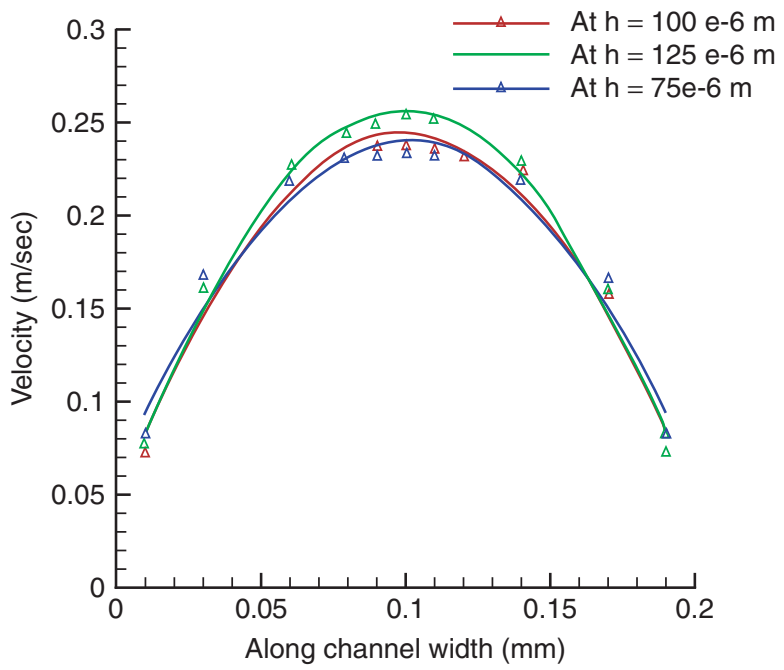

(b)

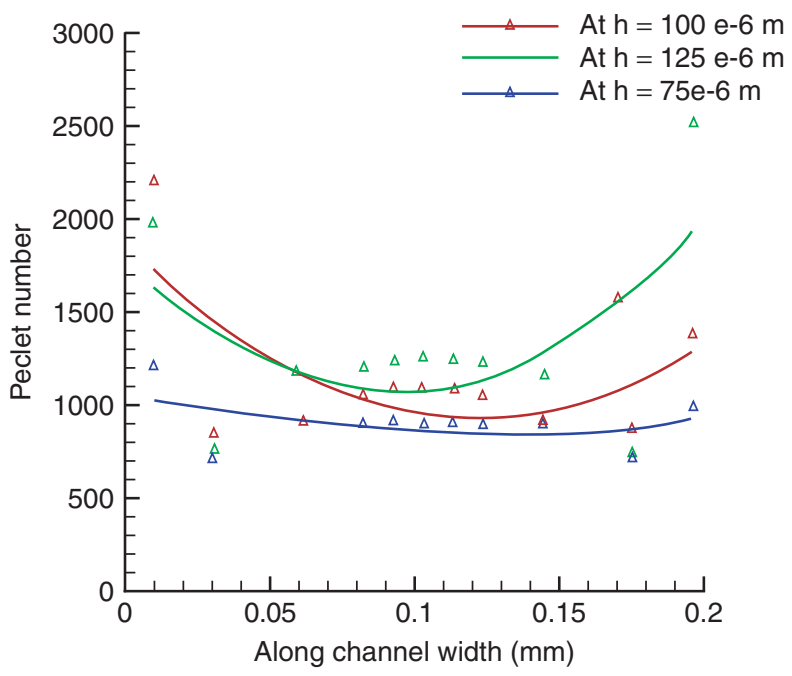

Figure 18 Variation of average velocity and Peclet number at different channel heights.

\subsection{EFFECT OF INLET FLOW ANGEL VARIATION}

This section presents the study to investigate whether the mixing angle has an effect on mixing length or not. Mixing angle can be defined as,' the angle between the inlet channel and the horizontal of mixing channel'. These analyses are done assuming a constant diffusion coefficient $1 \times 10^{-8} \mathrm{~m}^{2} / \mathrm{s}$, with an inlet velocity of $0.1 \mathrm{~m} / \mathrm{s}$ at both inlets. Mixing channel width is taken $200 \mu \mathrm{m}$ with a channel height of $100 \mu \mathrm{m}$. Analysis are done at four different inlet angels, $(0,15,30,45)$ degree to investigate the effect of change of inlet angle. Figure-20 $(\mathrm{a} \& \mathrm{~b})$ shows the variation of velocity and Peclet number with the variation of inlet flow angle.

Analysis of figure-20 (a\&b) shows that, there is no significant variation of average velocity in the mixing channel, which means that Reynolds number almost stay constant but variation of Peclet number shows an interesting behaviour, that with the increase of flow 


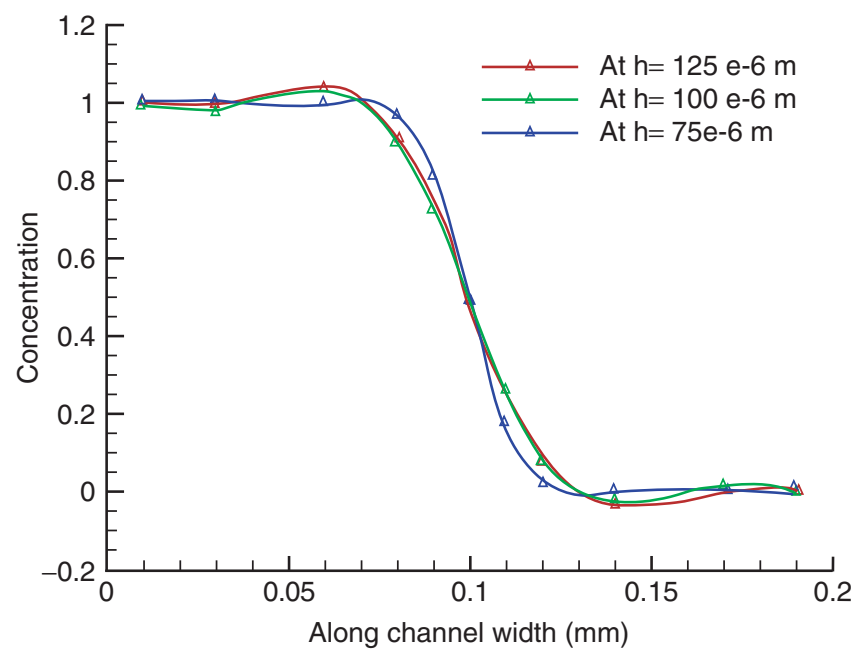

Figure 19 Variation of mixing concentration with channel height.

(a)

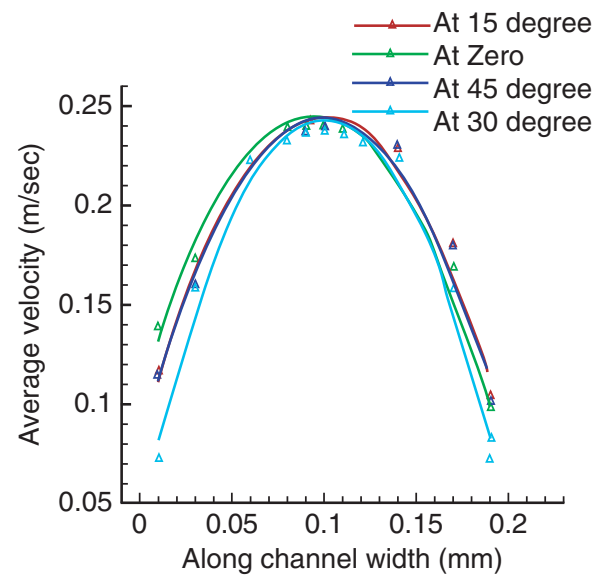

(b)

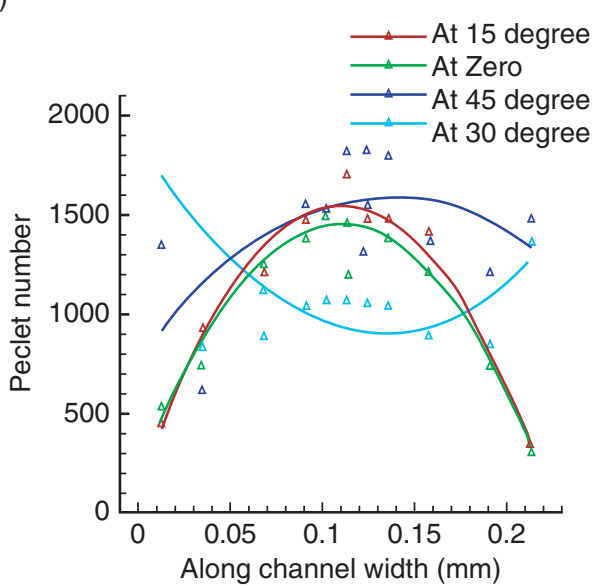

Figure 20 Variation of average velocity and Peclet number at different inlet angels.

inlet angle, mixing in channel becomes convection dominated, while at zero angle mixing is diffusion dominated in the centre of the channel. This might be due to variation of thickness of boundary layer across mixing channel walls. Due to variation of flow angle, flow from both the inlets meets an angle, which tends to increase the thickness of boundary layer near the walls, due to which flow near the walls becomes quits slow and leads to diffusion dominated near wall but in case of zero angel, mixing is diffusion dominated in the centre of the channel, and convection dominated near walls of channel, due to less thick boundary layer. But as an over all there is no considerable change in the mixing concentration with the variation of inlet flow angels. Figure-21 shows the variation of mixing concentration with the variation of inlet angel. 


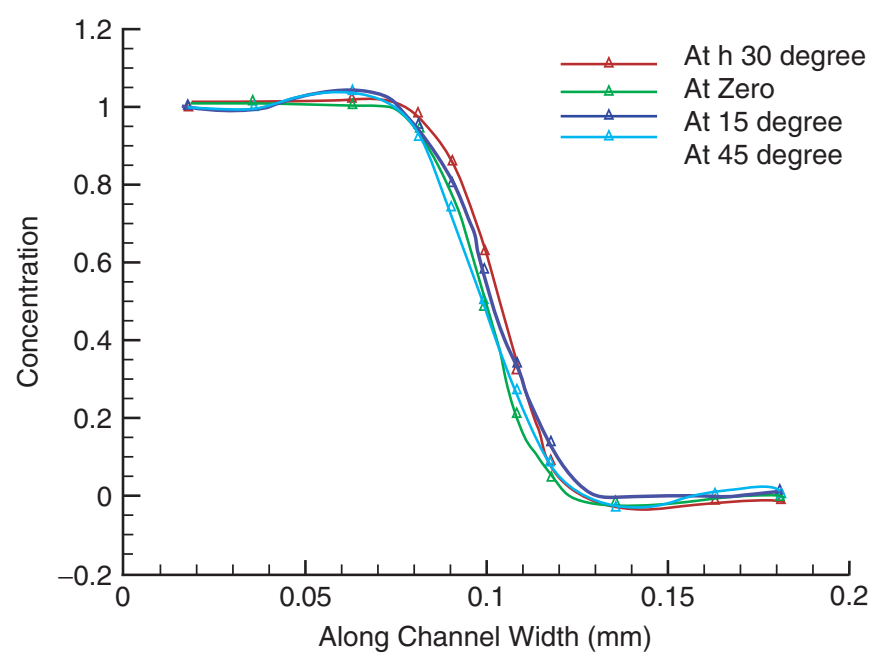

Figure 21 Variation of fluid concentration at different inlet angles.

\section{CONCLUSION}

Investigation of mixing characteristics in T-type passive micro mixer with the variation of flow and geometric parameters reveals that mixing length in $\mathrm{T}$ channel is highly influenced by variation of Reynolds number, Peclet number and geometric aspect ratio. Following are some important conclusions made upon the basis of results obtained from above mentioned investigation about mixing of fluids in T-type passive micro mixer.

- With the increase of inlet fluid velocity, Reynolds number increases to a considerable extant which leads to an increase in required mixing length to a considerable extent at all diffusion coefficients, which shows that a better mixing could be possible at low Reynolds number.

- Variation of diffusion coefficient leads to a variation in Peclet number. At low diffusion coefficient where the Peclet number is high, mixing length is higher compare to high diffusion coefficients, which means with the decrease of Peclet number mixing of fluid improves to a considerable extent.

- Variation of aspect ratio reveals that mixing length gets more influenced by variation of channel width instead of channel height. With the increase of channel width mixing length increases, but with the increase or decrease of channel height variation in mixing length is not considerable, which means that mixing in T type micro mixers is more influenced by variation of channel width, instead of variation of channel height.

- Variation of flow angle between inlet channels depicts that it does not have any considerable effect on mixing efficiency.

\section{NOMENCLATURE}

$\begin{array}{lll}\mathrm{c} & = & \text { Mixing concentration } \\ \mathrm{D} & = & \text { Diffusion coefficient } \\ \mathrm{L}_{\mathrm{m}}= & \text { Mixing length } \\ \mathrm{P}_{\mathrm{e}}= & \text { Peclet number } \\ \mathrm{R}= & \text { Rate of change of concentration }\end{array}$




$\begin{array}{lll}\mathrm{t}_{\mathrm{c}} & = & \text { Convective time } \\ \mathrm{t}_{\mathrm{d}} & = & \text { Diffusion time } \\ \mathrm{u}_{\mathrm{x}} & = & \mathrm{x} \text { - component of flow velocity } \\ \mathrm{u}_{\mathrm{y}}= & \mathrm{y} \text { - component of flow velocity } \\ \mathrm{u}_{\mathrm{z}}= & \mathrm{z} \text { - component of flow velocity } \\ \mathrm{w} & = & \text { Mixing channel width } \\ \eta & = & \text { Viscosity } \\ \rho & = & \text { Fluid density } \\ \mathrm{Z} & = & \text { Distance along } \mathrm{z} \text {-axis }\end{array}$

\section{REFERENCES}

1. A Maha, S.A. Soper. Simulation and design of micro mixers for microfluidic Devices, Microfluidics, BioMEMS and Medical microsystems. 2003. 5345:p. 183-193.

2. Wang X., Y. Huang, J Vykoukal, Cell seperation by dielectrophoretic field flow fractionation. Analytical Chemistry, 2000. 72: p. 832-839.

3. Shi, J. Scherer, D Wexler, Radial capillary array electrophoresis microplate and scanner for high nucliec acid analysis. Analytical Chemistry, 1999. 71(5354-5361).

4. P. Chariot, P. Sullivan, A study of Passive Microfluidic Mixers. 2004, University of Toronto: Toronto. p. 287293.

5. Y.C. Lu, Mixing Enhancement of passive microfluidic mixer with J shaped baffles in the tee channel. Biomed Microdevices, 2007. 9: p. 215-221.

6. J.M. Chen, W. Tan, Analysis and measurements of mixing in pressure driven mechanical flow. Microfluidic Nanofluid, 2006. 2: p. 455-469.

7. C. Hung, K. Wang, Design and flow simulation of a new micro mixer. JSME international Journal, 2005. 48(1): p. 17-24.

8. D. Gobby, Mixing charactristics of T-type microfluidic mixers. Journal of Micromechanics and microengineering, 2001. 11: p. 126-132.

9. P. Yager, A.E. Komholz, Therotical analysis of molecular diffusion in pressure driven laminar flow in microfluidic channels. Biophysics Journal, 2001. 80: p. 155-160.

10. D. Bothe, H.J. Warnecke, Fluid Mixing in a T-shaped micro mixer. Chemical Engineering Science, 2006. 61: p. 2950-2958.

11. D. Bokenkamp, X. Yang, and S. Mayo, Microfabricated Silicon Mixers for Submillisecond Quench-Flow Analysis. Analytical Chemistry, 1998. 70: p. 232.

12. T.M. Squires, Microfluidics: Fluid Physics at Nanoliter Scale. Review of Modern Physics, 2005. 77(July): p. 977-1017.

13. J. Green, A.E .Holdo, A. Khan, A review of Passive and Active Mixing Systems in microfliudic devices. Int Journal of Multiphysics, 2007, 1(1), pp: 1-36.

14. Bird R., Lightfoot E., Transport phenomena, ed. Willey. 1960, New York.

15. H. Wang, Passive mixing in micro channels with geomatric variations. 2004, Swinburne University of Technology, Hawthorn: Victoria. p. 225.

16. Purcell, Life at Low Reynolds number. American Journal of Physics, 1977. 45(1): p. 3-11.

17. Ismagilov, A.D. Stroock and G.Whitesides, Experimental and therotical scaling laws for transvers diffusive broadning in two phase laminar flows in microchannels. Applied physics letter 76, 2000: p. 2376-2378.

18. Le've^que, M.A., Les lois de la transmission de chaleur par convection. Ann. Mines., 1928. 13: p. 201-299

19. D. Gobby, Mixing Charactristics of T-type Microfluidic mixers. Journal of micromechanics and microengineering, 2001. 11: p. 126-132. 
